\title{
Effects of wall structure and light intensity on the settlement of a predatory mite, Euseius sojaensis (Ehara) (Acari: Phytoseiidae)
}

\author{
Tomohisa KaWASAKI, ${ }^{1, \dagger}$ Shuichi YANO ${ }^{2, *}$ and Mh. OSAKABE ${ }^{2}$ \\ ${ }^{1}$ Laboratory of Ecological Information, Faculty of Agriculture, and ${ }^{2}$ Laboratory of Ecological Information, Graduate School of \\ Agriculture, Kyoto University; Kyoto 606-8502, Japan
}

(Received 2 May 2008; Accepted 24 September 2008)

\begin{abstract}
We examined the effects of wall structure and light intensity on the settlement of the predatory mite Euseius sojaensis (Ehara). The mite preferred to settle beside higher walls and in wall gaps where it could make contact with two walls. Light intensity did not independently affect mite settlement; however, mites preferred to settle under moderate light near walls. These results suggest that a wall structure is an essential factor for mite settlement. These mites preferred to settle in the vicinity of leaf veins, which might be reflected in their preference for wall structures.
\end{abstract}

Key words: Wall structure; Euseius sojaensis; settlement; predatory mite; leaf vein

\section{INTRODUCTION}

Predatory mites prefer to settle in shelter-like microstructures such as tufts of hair or depressions on leaf surfaces (Walter, 1996). Shelter-dwelling is hypothesized to benefit predatory mites primarily by lowering their risk of predation by natural enemies (e.g., Norton et al., 2001). Although Grostal and O'Dowd (1994) suggested that shelter-like microstructures may benefit predatory mites by protecting them against low humidity, controlled experiments by Norton et al. (2001) revealed that such structures do not generally protect them from desiccation.

On the other hand, proximate factors by which predatory mites perceive shelter-like structures have never been addressed. Because predatory mites are promising biological control agents against spider mites that infest cultivated plants (McMurtry, 1982), elucidating these factors is important for efficiently retaining predatory mites on plants. Since any shelter-like microstructure consists of deviations from a plain surface, we reduced the physical properties of the microstructures to a common element: a wall structure. Predatory mites seem to perceive wall structures primarily by physical contact with the first legs, and then by contact with other legs and dorsal setae (Kawasaki, personal observation).

Furthermore, as shelter-like structures are accompanied by shade, i.e. lower light intensity, this would be perceived as a secondary cue of a shelterlike structure. Although predatory mites do not have eyespots, they respond to seasonal (Veerman, 1992) and diurnal (Onzo et al., 2003) photoperiods, suggesting that they perceive and somehow measure light intensity. Thus, we focused on two possible physical attributes of shelter-like microstructures in the settlement of the predatory mite Euseius sojaensis: contact with wall structures and light intensity.

\section{MATERIALS AND METHODS}

Mites. Euseius sojaensis is a generalist predatory mite that feeds on plant products and many spider mite species (e.g., Osakabe et al., 1986; Amano, 1996). We collected E. sojaensis from kudzu vines Pueraria lobata (Willd) Ohwi (Leguminosae) on the campus of Kyoto University and

\footnotetext{
* To whom correspondence should be addressed at: E-mail: yano@kais.kyoto-u.ac.jp

$\dagger$ Present address: Second Chemical Research Section, Research \& Development Laboratory, Dainihon Jochugiku Co., Ltd., Daikoku-cho, Toyonaka 561-0827, Japan.

DOI: 10.1303/aez.2009.81
} 


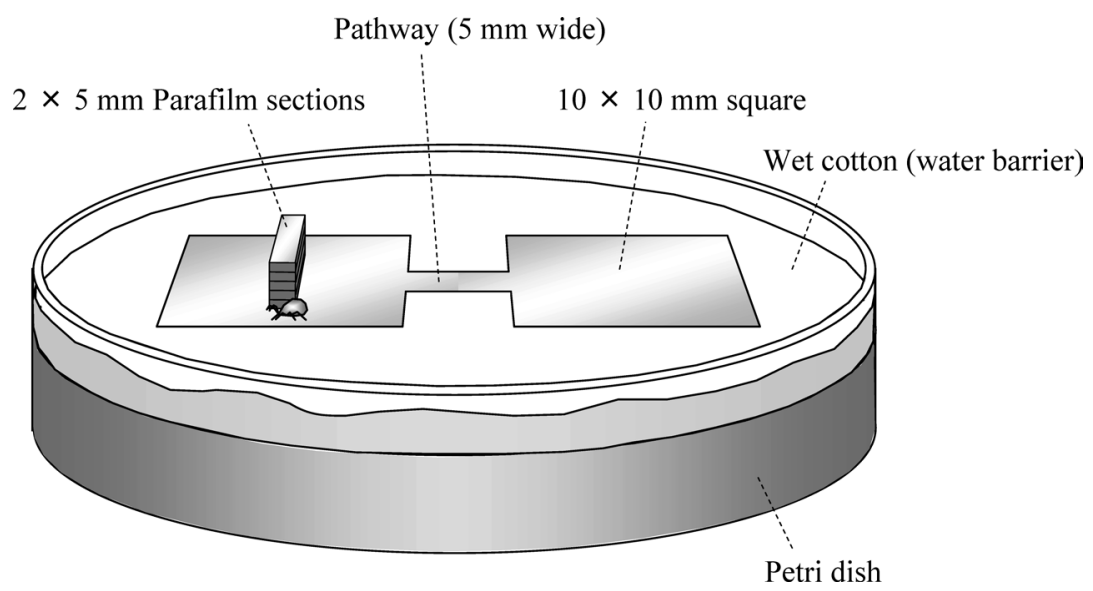

Fig. 1. Experimental design to examine the effect of wall structure on E. sojaensis settlement (five-ply vs. none).

reared them with tea pollen on $50 \times 50$-mm squares of Parafilm (Parafilm M; American National Can Co., Chicago, USA) placed on water-saturated cotton in Petri dishes $(90 \mathrm{~mm}$ in diameter, $14 \mathrm{~mm}$ in depth). All dishes were placed in transparent plastic containers and kept at $25^{\circ} \mathrm{C}$ and $50 \%$ relative humidity, with a photoperiod of 16L8D. All experiments were conducted under these conditions.

Effect of wall structure on $E$. sojaensis settlement. For the following dual choice tests, we placed a Parafilm sheet (hereafter, choice sheet) on the water-saturated cotton in Petri dishes $(90 \mathrm{~mm}$ in diameter, $14 \mathrm{~mm}$ in depth), where two equal squares were connected by a pathway (Fig. 1). To test for a preference to settle beside an object, we formed artificial wall structures using Parafilm pieces. Each Parafilm piece was $0.13 \mathrm{~mm}$ thick, or about half of the body height of an adult female $E$. sojaensis. We stacked five Parafilm sheets (i.e., $0.65 \mathrm{~mm}$ high), and cut them altogether into a $2 \times 5-\mathrm{mm}$ piece using a sharp cutter. Owing to the plasticity of Parafilm, the four side sections were plain; there was no space between each Parafilm piece. We then placed the Parafilm wall on one square of the choice sheet, while the other square served as a control (five-ply vs. none). We then introduced a 2- to 4-day-old adult female E. sojaensis in the middle of the pathway of each choice sheet using a fine brush. The females were not starved; they had been fed with ample pollen prior to the introduction. After $24 \mathrm{~h}$, we recorded the square on which E. sojaensis had settled. Females that stayed on the pathway or escaped from the choice sheet were excluded from analysis. The experiment was replicated 19 times. We also exam- ined one-ply vs. none (54 replicates) and five-ply vs. one-ply (19 replicates) in the same manner as described above. The numbers were compared using binomial tests, with the common null hypothesis that a female would settle on each of the two squares with equal probability (i.e., 0.5).

To further examine the preference for body contact with objects, we compared settlement beside (hereafter, wall side) and between (hereafter, wall gap) the wall structures. On a $20 \times 25-\mathrm{mm}$ Parafilm section, we created two Parafilm walls, each consisting of four $5 \times 10-\mathrm{mm}$ Parafilm sections (Fig. 2), $0.5 \mathrm{~mm}$ apart, which is slightly wider than the body width of an adult female E. sojaensis. Mites had the option of either settling along single walls or within the wall gap, where their bodies would make contact with two walls. The total length of the wall gap was $10 \mathrm{~mm}$, while that of all single walls was $40 \mathrm{~mm}$. We introduced a 2- to 4-day-old adult female onto each of the 18 Parafilm sheets. After $24 \mathrm{~h}$, the numbers of females settled at wall gaps and at wall sides were counted. The numbers were compared using a binomial test, with the null hypothesis that a female would choose the wall gap and the wall side with probabilities of 0.2 and 0.8 .

Effect of light intensity on $E$. sojaensis settlement. To examine the preference for light intensity, we covered each square of the choice sheet with a different shield: (1) overhead projector film (hereafter, transparent); (2) Parafilm (semitransparent); and (3) Parafilm colored with a black marker (black) (Fig. 3). The mean photon flux densities under the shields were 11.16, 10.32, and $0.74 \mu \mathrm{mol} \mathrm{m}{ }^{-2} \mathrm{~s}^{-1}$, respectively. The shields were placed $3 \mathrm{~mm}$ above the choice sheets, beyond the 


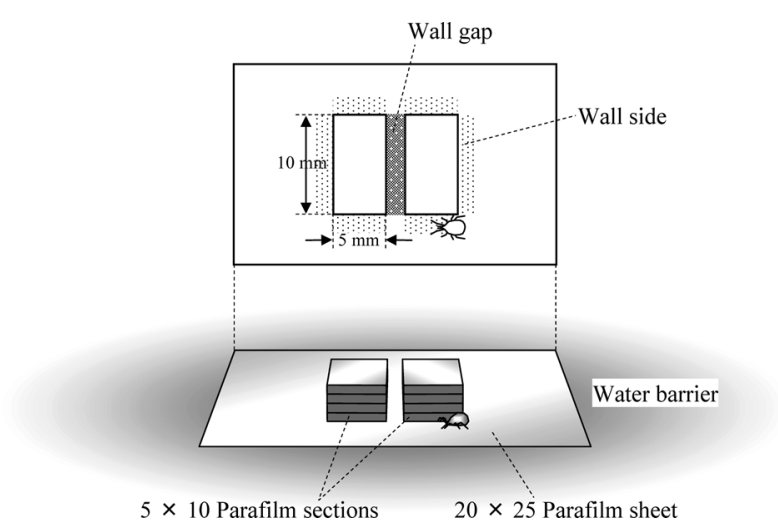

Fig. 2. Experimental design to examine the preference of E. sojaensis for wall gaps. The total length of the wall gap was $10 \mathrm{~mm}$, while that of the wall side was $40 \mathrm{~mm}$.

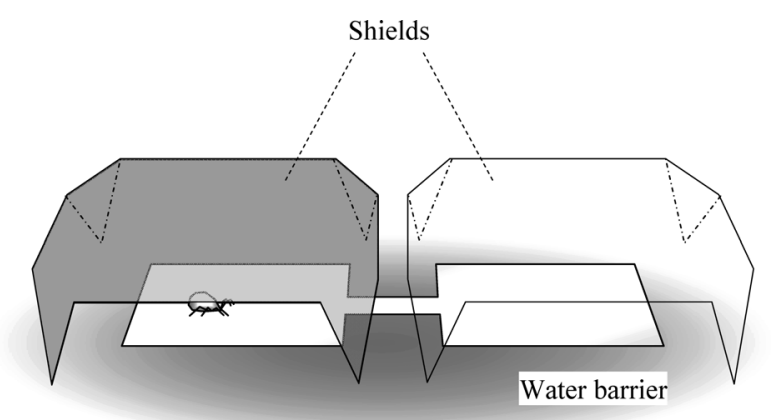

Fig. 3. Experimental design to examine the effect of light intensity on E. sojaensis settlement.

reach of test females. We compared two combinations of shields, semitransparent vs. transparent ( 72 replications) and semitransparent vs. black (74 replications). We introduced a 2- to 4-day-old adult female in the middle of the pathway. After $24 \mathrm{~h}$, we recorded the number of mites that settled under each of the two shields. The numbers were compared using binomial tests, with the common null hypothesis that a female would settle under each of the two shields with equal probability.

Moreover, we created a five-ply Parafilm wall on each of the two squares of a choice sheet in the same manner as described above and compared the two combinations of shields in the same way, to examine the preference for light intensity in the presence of wall structure.

Effect of leaf veins on $\boldsymbol{E}$. sojaensis settlement. To evaluate the preference of mites to settle near natural wall structures such as leaf veins, we cut a $10 \times 10-m m$ section from a kidney bean leaf (Phaseolus vulgaris L.) that contained a fragment of main vein parallel to any side of the square. The vein on the underside of the leaf was about $0.5 \mathrm{~mm}$ high, which was approximately equal to the body length of adult female E. sojaensis. The leaf square was placed underside up on the wet cotton, and a 2- to 4-day-old adult female was introduced onto the square. The experiment was replicated 16 times. After $24 \mathrm{~h}$, we recorded the position of settlement. Because adult female E. sojaensis were at most $0.5 \mathrm{~mm}$ long, the $1-\mathrm{mm}$-wide area along the vein was considered the vein side. Therefore, the number of mites that settled on the vein side vs. those that settled anywhere else was compared using a binomial test, with a null hypothesis that a female would choose the vein side and other areas with probabilities of 0.1 and 0.9 .

\section{RESULTS}

\section{Effect of wall structure on $E$. sojaensis settle- ment}

Although almost all E. sojaensis females seemed perturbed immediately after introduction, most settled within $24 \mathrm{~h}$. Significantly more mites settled beside five-ply walls than on squares with no walls (16:3, $p=0.002$, binomial test). They also preferred one-ply walls to nothing $(34: 20, p=0.038$, binomial test), and five-ply walls to one-ply walls (15:4, $p=0.01$, binomial test). Moreover, significantly more mites settled in wall gaps $(15: 3$, $p<0.001$, binomial test) than expected $(1: 4)$, indicating that they preferred wall gaps to wall sides.

\section{Effect of light intensity on $E$. sojaensis settle- ment}

A significant difference was not detected between semitransparent and transparent shields ( $40: 32, p=0.20$, binomial test) or between semitransparent and black shields $(40: 34, p=0.28$, binomial test). However, in the presence of a five-ply wall, significantly more mites settled under the semitransparent shield than the transparent shield (15:5, $p=0.02$, binomial test) and the black shield $(18: 2, p=0.0002$, binomial test).

\section{Effect of leaf veins on $E$. sojaensis settlement}

Significantly more mites settled on the vein side (9:7, $p<0.001$, binomial test) than expected ( $1: 9)$, indicating that they preferred vein sides. Seven females that did not settle on the vein side settled 
along minor veins and in the depressions of the leaf surface.

\section{DISCUSSION}

Predatory E. sojaensis mites preferred high walls to low walls, but also accepted walls as low as half of their body height. Moreover, they preferred wall gaps where they could make contact with two vertical walls to wall sides where they could only touch one wall. Therefore, body contact with wall structures seemed to be a primal factor affecting E. sojaensis settlement, although it is possible that relative humidity beside the Parafilm wall was different from the surrounding area, which may have affected E. sojaensis settlement. The preference of $E$. sojaensis for leaf veins may reflect its preference for wall sides, and its preference for wall gaps may correspond to its preference for plant microstructures such as leaf domatia and tomenta (Walter, 1996).

Settlement in small, sheltered spaces such as wall gaps would not prevent cannibalism (Schausberger, 2003), as conspecifics of the same size would also be able to access such sites; however, they would be effective against larger enemies of predatory mites such as pirate bugs and lady beetles (Cloutier and Johnson, 1993; Wittmann and Leather, 1997; Norton et al., 2001). From the viewpoint of predator avoidance, mites taking refuge in spaces where they can make contact with more than two walls would be better protected. This possible benefit may reflect their preference for invaginations in the leaf surface (Walter, 1996). The preference of E. sojaensis for higher walls can also be explained by that they would provide the mites with a larger dead angle from enemies and better protection as a result.

Although light intensity did not independently affect settlement, the mites preferred moderate light in the presence of wall structures. Such emergent preference may be explained as lower light levels accompanied by wall structures indicated 'roof structures', which may also protect mites from larger predators and/or stressful environmental conditions; however, the reason why moderate light was preferred remains to be investigated in the future.

\section{ACKNOWLEDGEMENTS}

We thank Dr. M. Fukaya and other members of the Laboratory of Ecological Information for valuable suggestions and encouragement. This study was partly supported by a Grantin-Aid for the Development of New Biorational Techniques for Sustainable Agriculture from the National Agriculture and Food Research Organization and a Grant-in-Aid for the 21st Century COE program of Innovative Food and Environmental Studies Pioneered by Entomomimetic Sciences at Kyoto University.

\section{REFERENCES}

Amano, H. (1996) Natural enemies. In Principles of Plant Acarology (S. Ehara and N. Shinkai, eds.). Zenkoku Noson Kyoiku Kyokai, Tokyo, pp. 159-174 (in Japanese).

Cloutier, C. and S. Johnson (1993) Predation by Orius tristicolor (Hemiptera: Anthocoridae) on Phytoseiulus persimilis (Acarina: Phytoseiidae): testing for compatibility between biocontrol agents. Environ. Entomol. 22: 477-482.

Grostal, P. and D. J. O'Dowd (1994) Plants, mites and mutualism: leaf domatia and the abundance and reproduction of mites on Viburnum tinus (Caprifoliaceae). Oecologia 97: 308-315.

McMurtry, J. A. (1982) The use of phytoseiids for biological control: progress and future prospects. In Recent $\mathrm{Ad}$ vances in Knowledge of the Phytoseiidae (M. A. Hoy, ed.). University of California, Berkeley, Publ. No. 3284, pp. 23-48.

Norton, A. P., G. English-Loeb and E. Belden (2001) Host plant manipulation of natural enemies: leaf domatia protect beneficial mites from insect predators. Oecologia 126: 535-542.

Onzo, A., R. Hanna, I. Zannou, M. W. Sabelis and J. S. Yaninek (2003) Dynamics of refuge use: diurnal, vertical migration by predatory and herbivorous mites within cassava plants. Oikos 101: 59-69.

Osakabe, Mh., K. Inoue and W. Ashihara (1986) Feeding, reproduction and development of Amblyseius sojaensis Ehara (Acarina: Phytoseiidae) on two species of spider mites and on tea pollen. Appl. Entomol. Zool. 21: 322-327.

Schausberger, P. (2003) Cannibalism among phytoseiid mites: a review. Exp. Appl. Acarol. 29: 173-191.

Veerman, A. (1992) Diapause in phytoseiid mites: a review. Exp. Appl. Acarol. 14: 1-60.

Walter, D. E. (1996) Living on leaves: mites, tomenta and leaf domatia. Annu. Rev. Entomol. 41: 101-114.

Wittmann, E. J. and S. R. Leather (1997) Compatibility of Orius laevigatus Fieber (Hemiptera: Anthocoridae) with Neoseiulus (Amblyseius) cucumeris Oudemans (Acari: Phytoseiidae) and Iphiseius (Amblyseius) degenerans Berlese (Acari: Phytoseiidae) in the biocontrol of Frankliniella occidentalis Pergande (Thysanoptera: Thripidae). Exp. Appl. Acarol. 21: 523-538. 